\title{
Correspondence
}

\section{Availability of dantrolene in Canadian hospitals}

To the Editor:

We read with interest Duncan's editorial on the availability of dantrolene in Canadian hospitals. ${ }^{1}$ Two years ago we wrestled with this problem when we were requested by the Alberta Medical Association to make a recommendation on how much dantrolene should be available in each hospital. Our conclusion was similar to Duncan's: that 12 vials, containing a total of $240 \mathrm{mg}$ of dantrolene, should be the minimum amount, with more available within a short time. Two hundred and forty $\mathrm{mg}$ would provide an initial dose of $3 \mathrm{mg} \cdot \mathrm{kg}^{-1}$ for patients weighing up to $80 \mathrm{~kg}$.

We have reviewed some of the case reports of malignant hyperthermia occurring after dantrolene prophylaxis. ${ }^{2,3}$ Often it is difficult to determine the precise dosage regimen from the report, ${ }^{3}$ and it is our feeling that adequate tissue levels have not been achieved in many of these cases. Administration of intravenous dantrolene immediately preoperatively, ${ }^{4}$ although expensive, may eliminate the occurrence of reactions after oral dantrolene pretreatment, and this is now our practice. Intravenous administration also eliminates the unpleasant side effects (weakness, blurred vision and nausea) of oral dosage over one or two days.

Overall, routine intravenous prophylaxis with an adequate dantrolene dose $\left(2.5-3.0 \mathrm{mg} \cdot \mathrm{kg}^{-1}\right)$ may be cheaper than treating occasional malignant hyperthermia reactions.

R. Paasuke MD CM FRCPC

Department of Anaesthesia

A.K.W. Brownell MD FRCPC

Department of Clinical Neurosciences

Foothills Hospital at the

University of Calgary

T2N 2T9
REFERENCES

1 Duncan PG. Availability of dantrolene in Canadian hospitals. Can Anaesth Soc J 1985; 32: 205-9.

2 Fitzgibbons $D C$. Malignant hyperthermia following preoperative oral administration of dantrolene. Anesthesiology 1981; 54: 73-5.

3 Ruhland $G$, Hinkle $A J$. Malignant hyperthermia after oral and intravenous pretreatment with dantrolene in a patient susceptible to malignant hyperthermia. Anesthesiology 1984; 60: 159-60.

4 Flewellen EH, Nelson TE. Prophylactic and therapeutic doses of dantrolene for malignant hyperthermia. Anesthesiology 1984; 61: 477.

\section{Massive haemorrhage during attempted laparoscopy}

To the Editor:

Massive haemorrhage is a recognised complication of laparoscopy. Puncture of the distal aorta ${ }^{1}$ or the iliac vessels ${ }^{2}$ and tearing of the broad ligament ${ }^{3}$ by the laparoscopic trocar or gas insufflation needle have been reported. Fortunately the incidence of haemorrhage is low. It has been reported as 0.64 per cent by Phillips ${ }^{4}$ who reviewed 100,000 pelvic laparoscopies.

We encountered a case of massive haemorrhage during attempted laparoscopy. A 33-year-old $60 \mathrm{~kg}$ female, ASA physical status I underwent general anaesthesia with endotracheal intubation for a scheduled laparoscopic tubal ligation. As the intraumbilical skin incision was made, a gush of blood was seen. Immediate pressure over the incision stopped any evidence of external bleeding. However, over the next three minutes the patient's vital signs deteriorated with an elevation in heart rate and a nonpalpable pulse. Immediate cardiopulmonary resuscitation was begun and emergency laparotomy quickly followed. A four millimeter laceration of the left common iliac artery just below the bifurca- 
tion of the aorta was repaired. The patient did well and was discharged on the eighth postoperative day.

This case serves to remind us that there are no minor operations. The scalpel blade is potentially a dangerous instrument even in the hands of an experienced and adept surgeon. For the safety of patients during any surgical procedure, no matter how minor it may appear, it is imperative that all members of the operating room team - surgeons, anaesthetists and nurses - are vigilant to detect the unexpected and are prepared to deal with it both promptly and with expertise.

\section{T.G. Mah MD FRCPC}

Department of Anaesthesia

UBC Health Sciences Centre Hospital

The University of British Columbia

Vancouver, B.C. V6T 2B5

\section{REFERENCES}

1 Chapin JW, Hurlbert BJ, Scheer BS. Hemorrhage and cardiac arrest during laparoscopic tubal ligation. Anesthesiology 1980; 53: 342-3.

2 Katz $M$, Beck $P$, Tancer $M L$. Major vessel injury during laparoscopy: anatomy of two cases. Am J Obstet Gynecol 1979; 135: 544-5.

3 McKenzie R. Laparoscopy. NZ Med J 1971; 74: 87-91.

4 Phillips $J M$. Complications in laparoscopy. Int $\mathrm{J}$ Gynecol Obstet 1977; 15: 157-62.

\section{Hyperventilation does not affect the incidence of pares- thesiae and blood vessel cannulation during epidural catheter insertion}

To the Editor:

Insertion of the epidural catheter during establishment of continuous epidural anaesthesia in obstet-
TABLE Results

\begin{tabular}{|c|c|c|c|c|}
\hline & \multicolumn{2}{|c|}{ Hyperventilation } & \multicolumn{2}{|c|}{ No hyperventilation } \\
\hline & No. of patients & $\%$ & No. of patients & $\%$ \\
\hline & 207 & & 188 & \\
\hline \multicolumn{5}{|l|}{ Needle } \\
\hline Blood & 14 & 7 & 12 & 6 \\
\hline Paresthesiae & 2 & 1 & 1 & 0.5 \\
\hline \multicolumn{5}{|l|}{ Catheter } \\
\hline Blood & 16 & 8 & 21 & 11 \\
\hline Paresthesiae & 73 & 35 & 50 & 26 \\
\hline
\end{tabular}

$\mathrm{P}=$ NS (Chi Square)

rics may cause paresthesiae. Blood vessel cannulation may also result, due in part to the presence of dilated epidural veins during pregnancy and labour.

One of us (A.R.) suggested that hyperventilation might reduce the incidence of paresthesiae and blood vessel cannulation. His practice has been to ask the patient to take five to six large breaths approximating vital capacity, immediately before insertion of the epidural catheter (Portex) through a \#16 Tuohy needle. Voluntary hyperventilation should lower the $\mathrm{PaCO}_{2}$ and possibly decrease the size of the epidural veins and thus reduce extent of trauma induced by the catheter.

In order to assess this practice we prospectively observed 395 patients who had epidural catheters inserted. The patients were selected at random and some were asked to hyperventilate as described above. All the epidurals were performed by staff anaesthetists.

Our results are shown in the Table. There was no difference in the occurrence of paresthesiae or cannulation of an epidural vein (Chi square). It is also of interest to note how frequently these events occur in everyday practice.
S.H. Rolbin FRCPC
A. Relle FRCPC
E.M. Hew FrCPC
Department of Anaesthesia
Mount Sinai Hospital
Toronto, Ontario
MSG 1X5 